\title{
Configurações
}

Revista de sociologia

\section{Introdução: profissões e trabalho na justiça}

Manuela Ivone Cunha, Ana Paula Marques and Rafaela Granja

\section{(2) OpenEdition}

\section{Journals}

Electronic version

URL: http://journals.openedition.org/configuracoes/2361

DOI: 10.4000/configuracoes.2361

ISSN: 2182-7419

\section{Publisher}

Centro de Investigação em Ciências Sociais

\section{Printed version}

Date of publication: 30 June 2014

ISBN: 1646-5075

ISSN: 1646-5075

Electronic reference

Manuela Ivone Cunha, Ana Paula Marques and Rafaela Granja, « Introdução: profissões e trabalho na justiça », Configurações [Online], 13 | 2014, Online since 17 April 2015, connection on 07 May 2019. URL : http://journals.openedition.org/configuracoes/2361 ; DOI : 10.4000/configuracoes.2361

This text was automatically generated on 7 May 2019.

(c) CICS 


\title{
Introdução: profissões e trabalho na justiça ${ }^{\text {[E] }}$
}

\author{
Manuela Ivone Cunha, Ana Paula Marques and Rafaela Granja
}

1 O presente número da revista Configurações procura contribuir para o estudo das tendências diversas que atravessam a justiça, as instituições e o trabalho social a ela ligados a partir do ângulo da atividade concreta e socialmente situada dos seus agentes magistrados judiciais e magistrados do Ministério Público, guardas prisionais, técnicos de reinserção social, profissionais de saúde nas prisões, entre outros.

2 Este estudo é tanto mais importante quanto se reconhece hoje que a ação pública e a atividade quotidiana das instituições na justiça e no trabalho social não relevam necessariamente de uma racionalidade uniforme. Em primeiro lugar, porque lógicas predominantes em diferentes momentos históricos raramente se sucedem de maneira absoluta, como se cada uma erradicasse a precedente para se instalar em lugar desta. Como referiu Michel Foucault (2004), pode suceder, em vez disso, que simplesmente mude a tónica ou o sistema de relações entre elas, ou ainda que tais lógicas coexistam em camadas compósitas nas práticas concretas e rotinas institucionais (cf. Cunha neste volume; Carlen e Tombs, 2006: 356; Shearing, 2001).

3 Em segundo lugar, o estudo da atividade concreta das instituições da justiça e do trabalho social na órbita desta é importante, na medida em que estas racionalidades tomam corpo através de uma variedade de atores com posições sociais, trajetos, disposições e culturas profissionais muito diversas. São estes atores, além disso, que tanto se podem instituir como fator de inércia quanto de mudança.

4 É em parte tendo em conta este tipo de aspetos que, como é referido mais adiante (ver Cunha neste volume), há quem defenda dever o Estado ser entendido menos como uma entidade una e singular, com limites precisos e agindo de maneira uniforme e consistente, e mais como uma teia diversificada de instituições, procedimentos e atores coexistindo de maneira complexa e por vezes contraditória (Ferguson e Gupta, 2002; Lipsky, 1980; Weller, 1999). Nesta linha, o estudo do Estado não pode, por seu turno, deixar de estar 
atento ao funcionamento concreto das suas instituições, nas quais políticas e práticas se cruzam e são produzidas na atividade quotidiana dos seus agentes.

Mais do que meros executantes de políticas, regras e orientações, estes atores não deixam de coproduzir, na prática, políticas e tendências, tanto na retaguarda como na linha da frente do contacto com o público (e.g., Dubois, 2010, 2012; Fassin, 2013; Israël, 2011; Lascoumes e Le Galès, 2012; Mainsant, 2013; Morgen, 2001; Serre, 2009; Spire, 2008). Fazem-no dentro de um quadro de ação composto por constrangimentos práticos específicos, por condições de trabalho, relações de poder, textos normativos e normas profissionais, mas também por configurações morais, ethos, valores e subjetividades várias (Fassin e Eideliman, 2012). É ainda neste quadro concreto e não isento de injunções por vezes divergentes ou mesmo conflituantes que se produzem, acoplados a saberes técnicos ou incrustados neles, "sensos comuns" específicos raramente explicitados.

Qual é, pois, o quadro de ação destes profissionais? Em que lógicas específicas se tem historicamente inscrito a sua atividade? Que reconfigurações têm sofrido os perfis e identidades profissionais nestas áreas? Que estratégias de credencialização e monopolização do mercado de trabalho têm sido desenvolvidas na sua relação com Estado, ordens ou associações profissionais? Em que medida os saberes e as competências mobilizados quotidianamente reforçam trajetórias de autonomização profissional ou, pelo contrário, são alvo de recomposições várias por força da intervenção em equipas multidisciplinares? Que deslocações têm ocorrido no centro de gravidade do seu métier? Que recentramentos tem conhecido a sua missão - por exemplo, entre o campo social e o jurídico; entre o cuidado, por um lado, e o controlo e avaliação de riscos, por outro; entre, por um lado, o trabalho no terreno ou o contacto face a face e, por outro, a formalização e a burocratização? Estas são algumas das questões que atravessam de forma direta ou indireta vários trabalhos neste número temático. Tais questões mostram também como pode ser útil aliar as abordagens neste âmbito a uma sociologia do trabalho, das profissões e dos grupos profissionais para o conhecimento quer do funcionamento de instituições em si, quer das dinâmicas, tendências e mecanismos concretos da ação pública. Ela pode, com efeito, contribuir para objetivar esse funcionamento, essas dinâmicas e esses mecanismos na prática, para os analisar para além dos discursos que os envolvem e para compreender como tomam forma através do sistema de relações entre diferentes profissões num mesmo meio institucional (e.g., Abbott, 1988; Avril, Cartier e Serre, 2010; Bezes et al., 2011; Chéronnet e Gadéa, 2009; Demazières e Gadéa, 2009).

o primeiro artigo deste volume alimenta o debate sobre o sistema de justiça e, em particular, sobre as transformações a que este tem vindo a ser submetido nos últimos anos. Tomando por base o período de vigência do programa de assistência económica e financeira em Portugal - que decorreu entre maio de 2011 e maio de 2014 -, Susana Santos explora as reformas operadas no sistema de justiça nacional. Através da análise do memorando de entendimento e das onze avaliações subsequentes, a autora evidencia como as modificações operadas na área da justiça emanam de um consenso entre elites políticas e elites jurídicas portuguesas que facilita a imposição de políticas reformistas com escasso ou inexistente apoio popular. Ao nível organizacional, a autora também destaca como as transformações são pautadas por uma racionalidade económica que, ao definir critérios de eficácia e eficiência mensuráveis, avalia os seus profissionais de acordo com o número de atos praticados num determinado período.

8 Seguidamente, João Paulo Dias, mantendo as lentes analíticas no sistema de justiça nacional, reflete sobre os desafios que as modificações em curso na área da justiça 
colocam ao Ministério Público. Salientando a particularidade da posição desta entidade cuja ação a coloca entre o sistema oficial de justiça e outras instituições estatais, civis e privadas -, o autor analisa as formas de relacionamento que cidadãos e instituições estabelecem com o Ministério Público nas diversas áreas de atuação. A sua reflexão apresenta o amplo conjunto de competências que o Ministério Público desempenha e sintetiza as exigências e desafios que atualmente se colocam aos seus magistrados. Por fi $\mathrm{m}$, reflete-se sobre as mudanças necessárias para garantir que este órgão desempenhe um papel decisivo na facilitação e promoção do acesso dos cidadãos ao direito e à justiça.

Mudando o enfoque para o sistema penal, Manuela Ivone Cunha traça o panorama atual da investigação prisional de terreno, identificando as suas linhas de desenvolvimento e agregando-as em torno do eixo da articulação entre o mundo intra e extramuros. Esta reflexão cruza diversas perspetivas e escalas de análise e expande o debate para além da produção científica norte-americana e anglófona. Em particular, o texto apresenta os desafios impostos pelas particularidades dos contextos prisionais aos investigadores; percorre e analisa as implicações das racionalidades, governamentalidades e políticas que têm vindo a enformar os sistemas penais, e, por fim, mostra como estudos recentes têm vindo a atribuir particular relevância às porosidades das fronteiras prisionais, exploradas tanto a partir do que a autora denomina de abordagens da "prisão-em-contexto" como através de abordagens de "interface".

Prosseguindo com temas fundeados no contexto prisional, Ana Pereira Roseira apresenta os resultados de uma investigação que visa mapear as perceções dos profissionais do sistema penal, e em particular dos guardas prisionais, sobre o funcionamento das prisões e sobre as suas experiências laborais. Neste texto, a autora empreende uma análise na qual procura desconstruir três principais lugares-comuns relativos ao papel dos guardas, designadamente: $i$ ) a perpetuação da ideia de que os guardas são os "antigos carcereiros"; ii) a noção de que a formação destes agentes é uma tendência recente; iii) a perceção de que paulatinamente os guardas estão a ser integrados nos sistemas prisionais enquanto agentes de reeducação. Através da sua reflexão historicamente informada, a autora atribui especial destaque à informalidade que constrói e constitui o papel dos guardas nos estabelecimentos prisionais portugueses.

11 Dando continuidade à discussão em torno das profissões exercidas nas prisões, Yasmine Bouagga, partindo da sua etnografia em duas prisões francesas, apresenta um artigo que explora as reconfigurações que os perfis e as identidades profissionais dos técnicos de reinserção social têm sofrido. Integrando na sua análise as dinâmicas plurais que caracterizam a esfera penal, os desafios impostos pela sobrepopulação prisional, as reformas humanistas e os constrangimentos administrativos nas prisões, a autora mostra como o papel dos técnicos de reinserção social tem vindo a deslocar-se do serviço social para o campo da "avaliação criminológica". Este deslocamento, para além de exigir o ajustamento a novas funções, práticas, subjetividades e configurações morais, implica que estes profissionais se posicionem numa situação ambígua que alterna entre funções de proteção e de punição. Situando-se agora na zona de articulação entre o "penitenciário" e o "judiciário", as transformações deste grupo profissional dão elas próprias a ver algumas das mutações da instituição prisional.

Concluindo as abordagens centradas no meio prisional, Gloria Jólluskin Andreia de Castro-Rodrigues, Isabel Silva e Verónica Fernandes trazem uma contribuição que reflete sobre o papel dos profissionais de saúde em contextos de reclusão. Através de uma abordagem direcionada para a intervenção, as autoras apresentam os principais desafios 
e dificuldades com que estes profissionais se podem confrontar, maioritariamente relacionados com as particularidades da população que assistem - a qual apresenta um nível de saúde significativamente inferior ao da população geral - e as características distintivas do meio em que trabalham. Discutindo a necessidade de fomentar a comunicação e a literacia em saúde, as autoras sistematizam recomendações que integram um conjunto de medidas e princípios norteadores que visam a promoção da saúde em meio prisional.

De seguida, o texto de Tânia Azevedo e Vera Duarte aborda a intervenção com jovens delinquentes no sistema de justiça juvenil. Baseando-se numa investigação de carácter qualitativo, as autoras exploram as perceções sobre esta problemática a partir da perspetiva dos jovens a cumprir medida de internamento e dos profissionais que trabalham no Centro Educativo. Os dados revelam a importância que tanto jovens como profissionais atribuem à esfera educativa e relacional da intervenção. Porém, os resultados também destacam as fragilidades deste modelo de intervenção. Estas prendemse maioritariamente com a exígua participação da família no cumprimento da medida e com as escassas pontes estabelecidas com os jovens após a saída da instituição.

14 A encerrar este número sobre trabalho e justiça, Lurdes Guerra e Pedro Cunha fazem incidir a sua reflexão sobre os Julgados de Paz, que constituem um dos meios alternativos de gestão de conflitos existentes em Portugal. Através de uma metodologia quantitativa, os autores exploram a mediação realizada nestes contextos a partir da perspetiva dos atores profissionais que nela intervêm, designadamente, juízes de paz, mediadores e advogados. Os resultados evidenciam uma perceção concertada de cariz positivo, tanto face às características estruturais dos Julgados de Paz - que integram dimensões como a localização, a qualidade das instalações e as competências destes meios alternativos de resolução de divergências -, como no que respeita ao serviço de mediação. Neste domínio em concreto é sublinhada a utilidade da mediação no estabelecimento de diálogos construtivos e de acordos satisfatórios para os envolvidos.

O conjunto de contribuições para este volume resultou, em suma, de uma aposta que julgamos conseguida em entrosamentos vários: interdisciplinares, intra e extra institucionais, entre ensino e formação pós-graduada e, sobretudo, entre áreas temáticas que raramente se cruzam.

\section{BIBLIOGRAPHY}

Abbott, Andrew (1988), The System of Professions: An essay on the division of expert labor. Chicago: University of Chicago Press.

Avril, Christelle; Cartier, Marie; Serre, Delphine (2010), Enquêter sur le travail: concepts, méthodes, récits. Paris: La Dé couverte.

Bezes, Philippe; Demazière, Didier; Le Bianic, Thomas; Paradeise, Catherine; Normand, Romuald; Benamouzig, Daniel; Pierru, Frédéric; Evetts, Julia (2011). “New Public Management et 
professions dans l'État : au-delà des oppositions, quelles recompositions?" Sociologie du Travail 53 (3): 293-348.

Carlen, P.; Tombs, J. (2006), “Reconfigurations of penality. The ongoing case of the women's imprisonment and reintegration industries", Theoretical Criminology, 10 (13), 337-60.

Chéronnet, Hélène; Gadéa, Charles (2009), "Les cadres du travail social et de la santé face à la rationalisation managériale des services publics". In C. Gadéa e D. Demazière (eds.), Sociologie des groupes professionnels, Paris: La Découverte: 73-83.

Demazière, Didier; Gadéa, Charles (2009), Sociologie des groupes professionnels: acquis récents et nouveaux défis. Paris: La Découverte.

Dubois, Vincent (2010) [1999], The Bureaucrat and the Poor. Encounters in French Welfare Offices, Aldershot, Ashgate,

Dubois, Vincent (2012), “Ethnographier l'action publique”. Gouvernement et action publique, 1 (1): 83-101.

Fassin, Didier; Eideliman, Jean-Sébastien (eds.) (2012), Économies morales contemporaines. Paris: La Découverte.

Fassin, Didier; Eideliman, Jean-Sébastien (eds.) (2013) [2011], Enforcing Order: An ethnography of urban policy. Cambridge: Polity Press.

Ferguson J.; Gupta, A. (2002), “Spatializing states: toward an ethnography of neoliberal governmentality”, American Ethnologist, 29 (2), 981-1002.

Foucault, Michel (2004), Sécurité, territoire, population. Cours au Collège de France, 1977-1978. Paris: Seuil/Gallimard.

Israël, Liora (2007), “Quand les professionnels de justice revendiquent leur engagement”. In Jacques Commaille e Martine Kaluszynski (eds.) La Fonction politique de la justice. Paris: La Dé couverte.

Lascoumes, Pierre; Le Galès, Patrick (2012), Sociologie de l'action publique. Paris: Armand Colin.

Lipsky M. (1980), Street-Level Bureaucracy: Dilemmas of the individual in Public Services. New York: Russel Sage Foundation.

Mainsant, Gwénaëlle (2013), «Gérer les contradictions du droit 'par le bas'. Logiques de police en concurrence dans le contrôle de la prostitution de rue à Paris», Actes de la Recherche en Sciences Sociales 198: 23-34.

Morgen, Sandra (2001), “The agency of welfare workers: Negotiating devolution, privatization, and the meaning of self-suffi ciency". American Anthropologist, 103 (3): 747-761.

Serre, Delphine (2009), Les Coulisses de l'Etat social: enquête sur les signalements d'enfant en danger. Paris: Raisons d'agir.

Shearing, C. (2001), "Punishment and the changing face of governance", Punishment and Society, 3 (2), 203-20.

Spire, Alexis (2008), Accueillir ou reconduire: enquête sur les guichets de l'immigration. Paris: Raisons d'agir.

Weller, Jean-Marc (1999), L'État au guichet: sociologie cognitive du travail et modernisation administrative des services publics. Paris: Desclée de Brouwer. 


\section{NOTES}

[5. O presente dossiê teve origem nas III Jornadas do Mestrado em Crime, Diferença, Desigualdade, subordinadas ao tema Trabalho e Identidades Profissionais em Questão na Justiça e na Intervenção Social (Universidade do Minho, 6 de junho 2014). Agradece-se aos participantes que se dispuseram a reelaborar a sua intervenção nas jornadas sob a forma de artigo, bem como aos que entretanto se juntaram a este volume de contribuições.

\section{AUTHORS}

\section{MANUELA IVONE CUNHA}

CRIA-UMinho - Universidade do Minho

\section{ANA PAULA MARQUES}

CICS - Universidade do Minho

RAFAELA GRANJA

CICS - Universidade do Minho 